Original article

Received: 27 October 2016 / Accepted: 14 June 2017

\title{
INVESTIGATION OF CHANGES OF THE KINEMATIC PARAMETERS OF ANTARCTIC TECTONIC PLATE USING DATA OBSERVATIONS OF PERMANENT GNSS STATIONS
}

\author{
Kornylii Tretyak, Al-Alusi Forat, Yurii Holubinka \\ Institute of Geodesy \\ Lviv Polytechnic National University
}

\begin{abstract}
The paper describes a modified algorithm of determination of the Euler pole coordinates and angular velocity of the tectonic plate, considering the continuous and uneven distribution of daily measurements of GNSS permanent stations. Using developed algorithm were determined the mean position of Euler pole and angular velocity of Antarctic tectonic plate and their annual changes. As the input data, we used the results of observations, collected on 28 permanent stations of the Antarctic region, within the period from 1996 to 2014.
\end{abstract}

Keywords: GNSS, Euler pole, Antarctic tectonic plate

\section{Main directions of geodynamic research in Antarctica.}

A unique geophysical and geodynamic environment of Polar Regions can be characterized by tie connection between solid earth, cryosphere, hydrosphere, and atmosphere. Geodetic and geophysical observations in permanent and temporary stations play a significant role in a scientific research of the processes, and are directly connected with global climate changes. Within the last 25 years there have been established many geodetic observatories in the Antarctic. The observations methods include Global Navigation Satellite System (GNSS) - GPS, GLONASS , GALILEO, Doppler Orthography and Radiopositioning Integrated by Satellite (DORIS) - tidal, absolute and relative gravimetric, seismic and meteorological observations.

Expert Group was established in the framework of Scientific Community of Antarctic Research (SCAR) and Geodetic Infrastructure of Antarctica (GIANT). This group plays a significant role in coordination and development of international geodetic and geophysical infrastructure and projects in Antarctica (Scientific Community of Antarctic Research - 2016). 
Due to complicated climatic conditions, geodynamic research in Antarctica is substantially limited in space. In accordance with this, research of some Antarctic regions is uneven in time and space. Even for today, most part of Antarctica is a "white spot" in terms of field geodynamic observations (Fig. 1).

The main goal of the first GPS measurements was the development of the highly precise geodetic network in Antarctica and determination of relative velocities and directions of Antarctic plate in the International Terrestrial Reference System (Johnstone, 2002; Dietrich, Rulke, 2008).

For investigation of local geodynamic crustal movements, a number of projects were established: Victoria Land Network for DEFormation (VLNDEF) and Transantarctic Mountain DEFormation (TAMDEF) (Capra, et. al., 2008). In the framework of these projects there were investigated the Earth crust deformations of Transantarctic mountains in the Victoria Land region, and the connection between crust vertical movements and glacier-isostatic adjustment. In addition, there was found a rock uplift in Victoria Land region with the average velocity of $4 \mathrm{~mm} /$ year (Capra, et. al., 2002, 2008).

Within the period from 2001 to 2006 on the Western Antarctic territory, there was established West Antarctic GNSS network (WAGN). This network covers the territory along West-Antarctic Ice Cup from the Ross Sea to the Weddell Sea, and from the Pacific Ocean coast to the Transantarctic Mountains. The results of investigation carried out in the region showed the increase of tectonic activity, in particular, uplift and horizontal movements of the Transantarctic Mountains. Melting of Antarctic Ice Cup and tectonic activity of the regional tectonic faults (Dalziel, et. al. 2006) were considered the possible reasons.

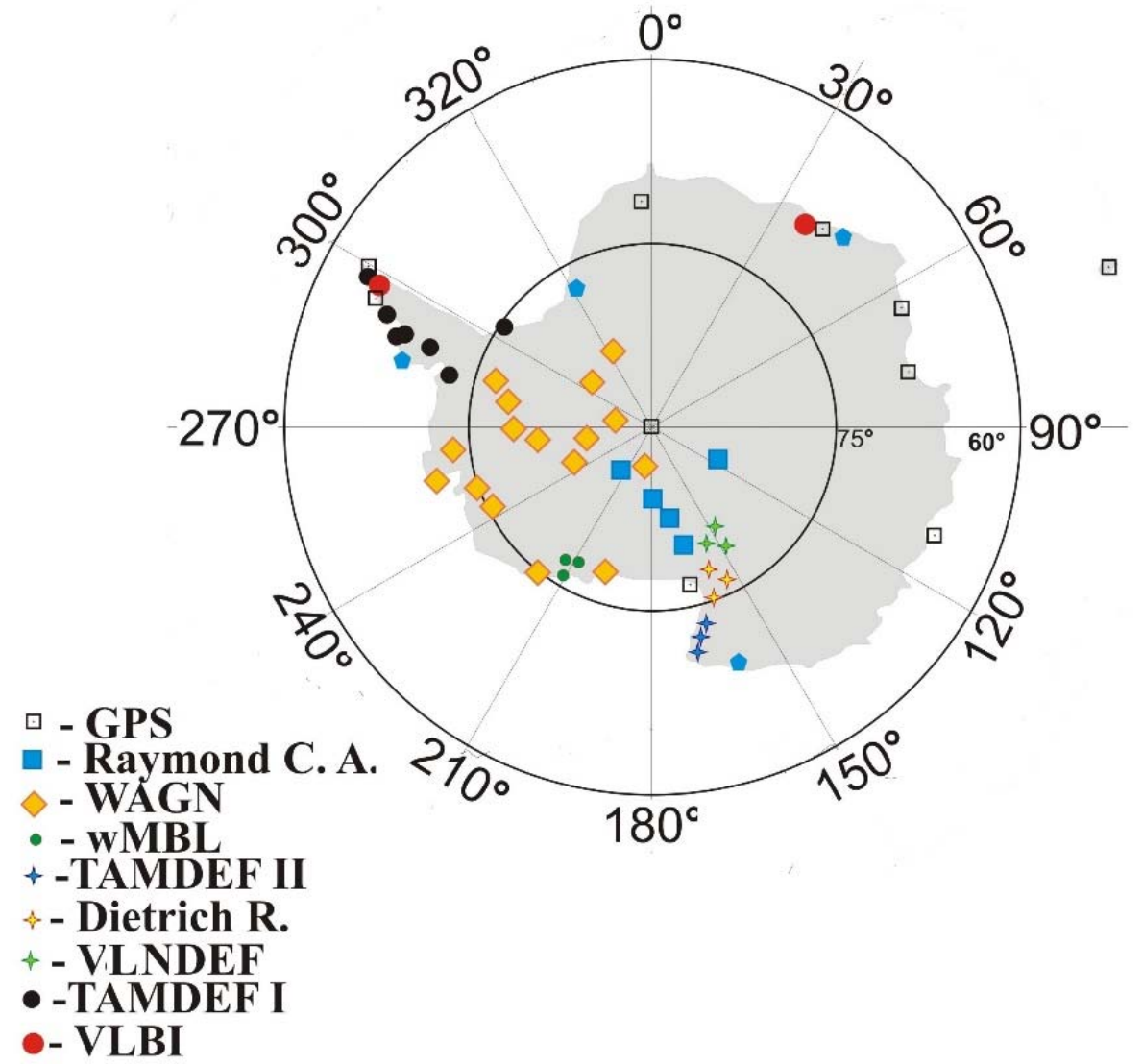

Fig. 1. Regional geodynamic research in Antarctica 
The next important object of the geodynamic research in Antarctica is Merry Bird Land. It is one of the Antarctic microplates, which forms West Antarctica. The results of GNSS observations analysis showed minor spreading among Ross bay between GNSS stations (MCM4 and WMBL) (Donnellan, Luyendyk, 1999, 2004). Determined horizontal velocities are within $2.3-1.3 \mathrm{~mm} /$ year. It obviously indicates that tectonic activity in the Antarctic rift zone is minimal.

Within the period from 2007 to 2008, under the program of International Polar Year there was developed a project "Earth Polar Observations Networks" - Polenet, which was focused on geodetic-geodynamic researches in Antarctica. Special attention was concentrated on the development of global and regional models (geodynamics, tectonic plates, postglacial rebound and climate systems) and investigation of its changes in time.

Special attention in scientific research of Antarctica is dedicated to investigation of the interconnection between the climate changes and modern movements of the Earth crust. Thus, in the paper (Nield, 2014) continuous GNSS observations on PALM permanent station and on 6 stations of the LARsen Ice Shelf System Antarctica network (LARISSA) for the period of 1998.5-2013, were used for investigation of the response of low-viscosity solid Earth on the unloading of ice-mass in Antarctic Peninsula region (Nield, 2014).In paper (Berrocoso, 2016), the regional geodynamic model of the South Shetland Islands and the Bransfield Basin region was proposed. This model was established based on GNSS observations conducted, during 2002 2014 on the 9 geodetic benchmarks located the research region. Computed horizontal velocity vectors showed opening of the Bransfield Basin. Subsidence of the benchmarks, located on the Shetland Islands, according to the authors, might be a consequence of tectonic activity of the South Shetland Trench. Uplift of the Antarctic Peninsula benchmarks authors explained as an effect of glacial isostatic adjustment after the Larson B ice-shelf breakup (Berrocoso, 2016).

As follows, the continental geodynamic model of Antarctica has been established based on the results of complex geological and geophysical investigations. Over the last 20 years, this model has been much updated thanks to the precise geodetic measurements. The measurements of the permanent GNSS network of Antarctica is the main data source, which allows monitoring the recent movements of Antarctic tectonic plate.

The investigation of the Antarctic tectonic plate kinematics is very important for the search of possible dominate factors of whole lithosphere motions. With respect to the tectonic plate's theory, the main cause of these motions is a mantle convection. Nevertheless, this theory does not consider the influence of planetary forces (caused by the Earth rotation, Coriolis forces).

The purposes of the work is Investigation of kinematic parameters of the Antarctic tectonic plate and annual changes of its angular velocity and Euler pole position, using GNSS data.

\section{Research results.}

For investigation of rotational motions of Antarctic tectonic plate, we used results of GNSS observations from 28 stations, located on the Antarctic plate for time period 1996 - 2014 (fig. 2). Coordinates of these stations are displayed in Tab. 1. 


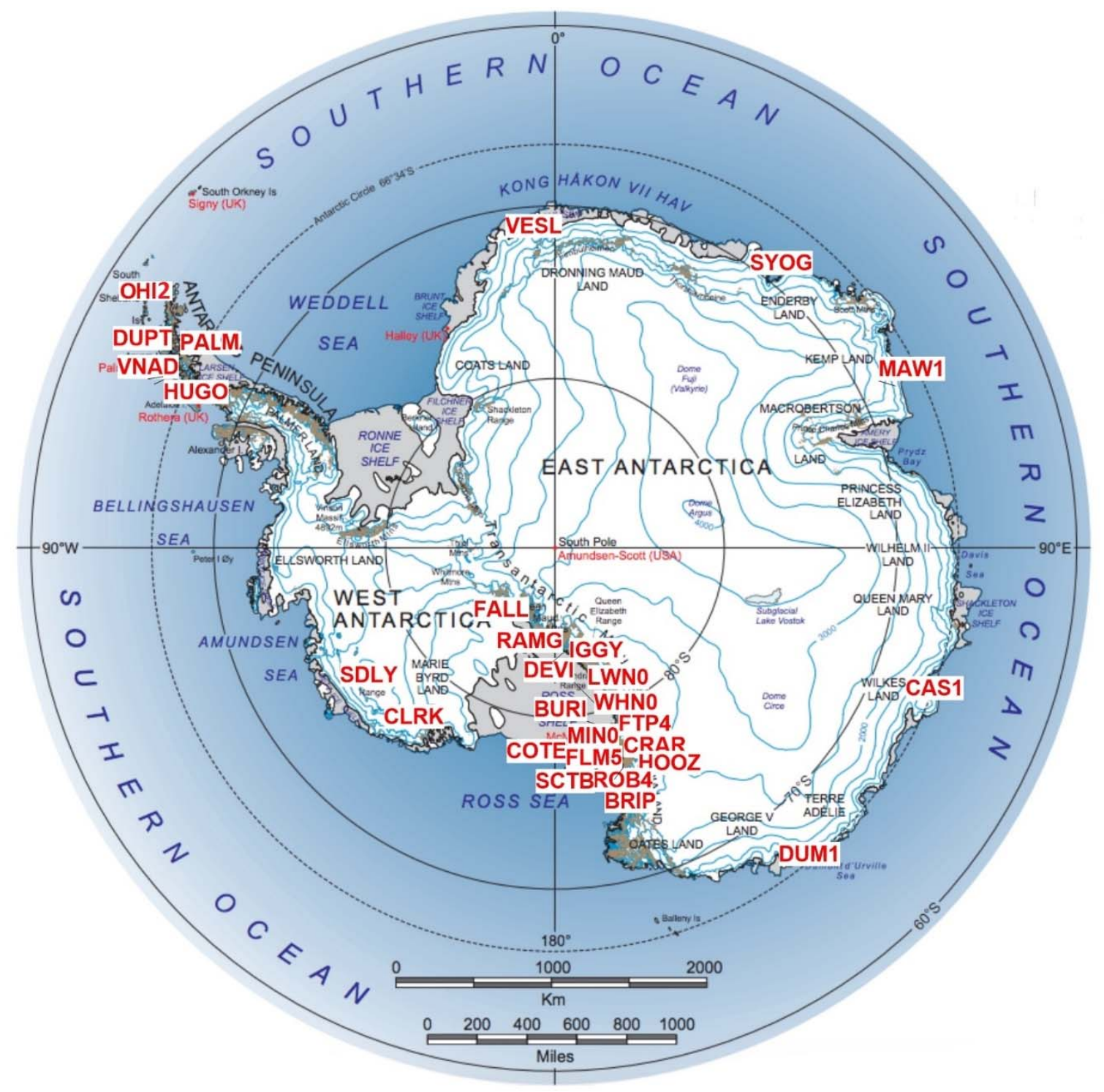

Fig. 2. Location of permanent GNSS stations in Antarctica

Daily solutions of each station, were computed by the Nevada Geodetic Laboratory (NGL, 2016) using GIPSY-OASIS-II software with Precise Point Positioning strategy, and daily station coordinates are available on the web-site NGL in IGS08 reference frame.

From the fig. 3 we can see, that position of GNSS stations is non-uniform, it is caused by difficulties in the exploration of Antarctica. Besides, the collected observations are not uniform in time. Table 2 shows availability of daily solutions for each station by the years of observations.

Analysis of table 2 allows distinguishing five GNSS stations: CAS1, DUM1, MAW1, PALM, SYOG, VESL, which have the longest series of observations of about 20 years. Starting from 2010, time series are almost uniform and continuous. 
Table 1. Geodetic coordinates of the selected stations, downloaded from GNSS database of the Nevada Geodetic Laboratory (NGL, 2016)

\begin{tabular}{|c|r|r|r|}
\hline $\begin{array}{c}\text { Station } \\
\text { name }\end{array}$ & $\mathrm{B}\left[{ }^{\circ}\right]$ & \multicolumn{1}{c|}{$\mathrm{L}\left[{ }^{\circ}\right]$} & \multicolumn{1}{c|}{$\mathrm{H}[\mathrm{m}]$} \\
\hline BRIP & -75.80 & -201.53 & 2110.910 \\
\hline BURI & -79.15 & -204.11 & 2006.304 \\
\hline CAS1 & -66.28 & -249.48 & 22.443 \\
\hline CLRK & -77.34 & -141.87 & 999.827 \\
\hline COTE & -77.81 & -198.00 & 1878.395 \\
\hline CRAR & -77.85 & -193.33 & -19.811 \\
\hline DEVI & -81.48 & -198.02 & 67.011 \\
\hline DUM1 & -66.67 & -220.00 & -1.326 \\
\hline DUPT & -64.80 & -62.82 & 43.466 \\
\hline FALL & -85.31 & -143.63 & 260.186 \\
\hline FLM5 & -77.53 & -199.73 & 1869.726 \\
\hline FTP4 & -78.93 & -197.44 & 243.223 \\
\hline HOOZ & -77.53 & -193.07 & 2070.409 \\
\hline HUGO & -64.96 & -65.67 & 20.638 \\
\hline IGGY & -83.31 & -203.75 & 1898.167 \\
\hline LWN0 & -81.35 & -207.27 & 1528.537 \\
\hline MAW1 & -67.60 & -297.13 & 59.141 \\
\hline MIN0 & -78.65 & -192.84 & 676.908 \\
\hline RAMG & -84.34 & -181.95 & 1062.348 \\
\hline ROB4 & -77.03 & -196.81 & -41.611 \\
\hline SCTB & -77.85 & -193.24 & -18.926 \\
\hline SDLY & -77.14 & -125.97 & 2097.301 \\
\hline SYOG & -69.01 & -320.42 & 50.011 \\
\hline VESL & -71.67 & -2.84 & 862.380 \\
\hline VNAD & -65.25 & -64.25 & 20.990 \\
\hline WHN0 & -79.85 & -205.78 & 2192.643 \\
\hline OHI2 & -63.32 & 302.09 & 32.524 \\
\hline PALM & -64.77 & 295.94 & 31.059 \\
\hline
\end{tabular}

The connection between velocity of permanent GNSS station displacement and Euler pole parameters: coordinates and plate rotation velocity (fig.3) can be displayed by following formulae:

$$
\begin{gathered}
V_{B}=\Omega \cdot \cos (\Phi) \cdot \sin (L-\Lambda) \\
V_{L}=\Omega \cdot(\sin (\Phi) \cdot \cos (B)-\cos (\Phi) \cdot \sin (B) \cdot \cos (L-\Lambda))
\end{gathered}
$$

where $\Omega$ - is angular rotation velocity of tectonic plate; $\Phi, \Lambda$ - Euler pole latitude and longitude; $L, B$ - permanent GNSS station latitude and longitude; $V_{B}, V_{L}$ - permanent GNSS station velocity vector components. 


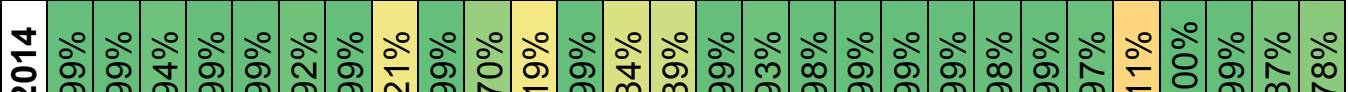
m

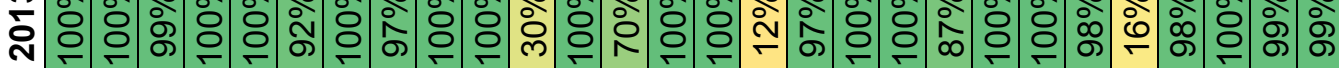
พิ

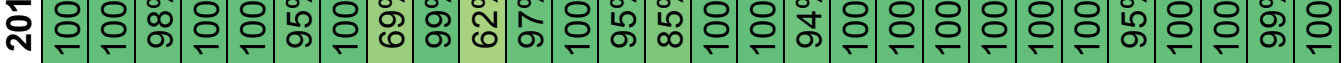

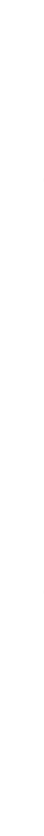

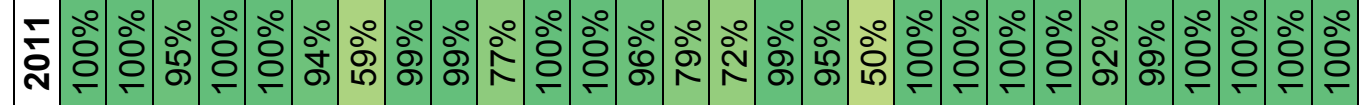

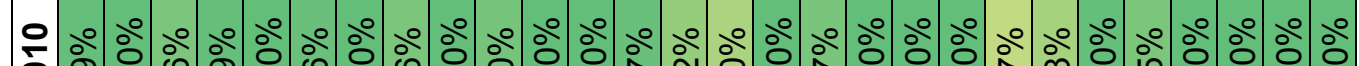
হి

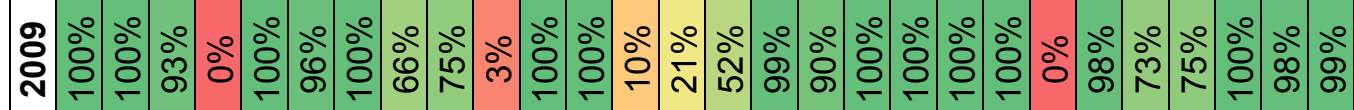

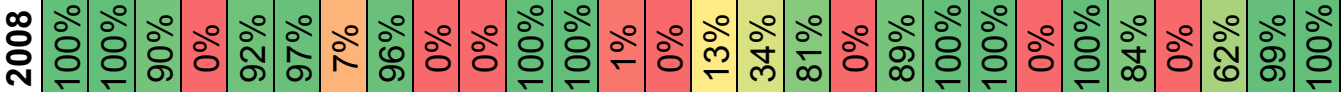

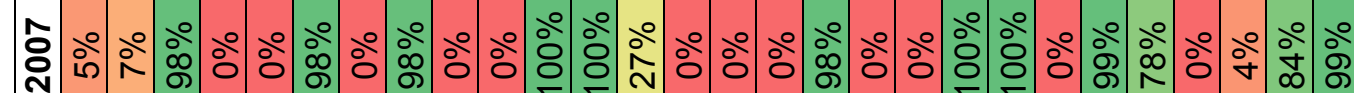

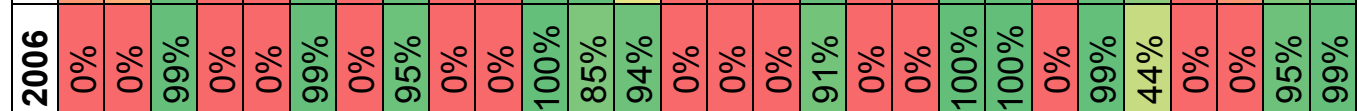
రి N

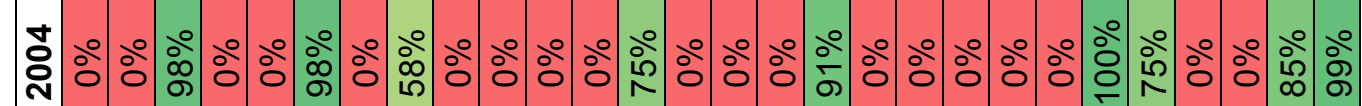

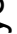
ลิ

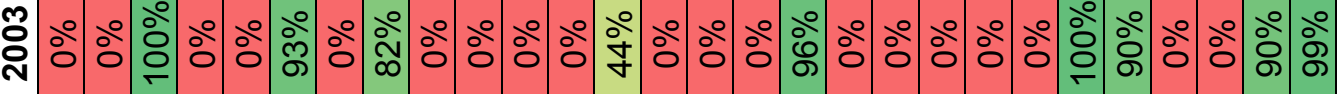

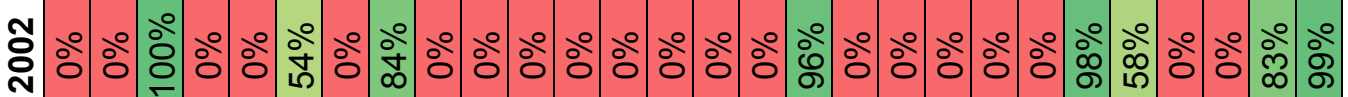

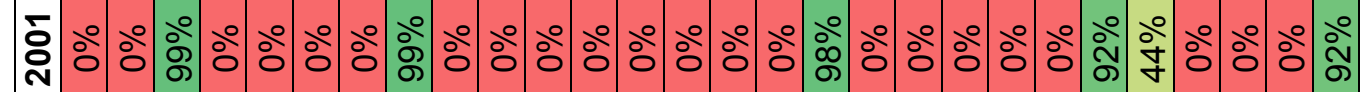

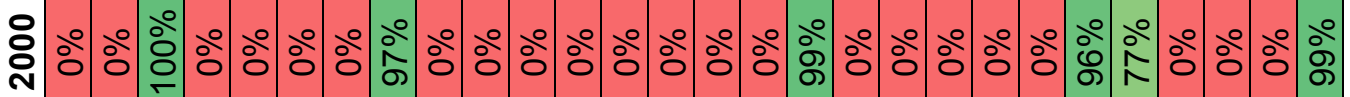

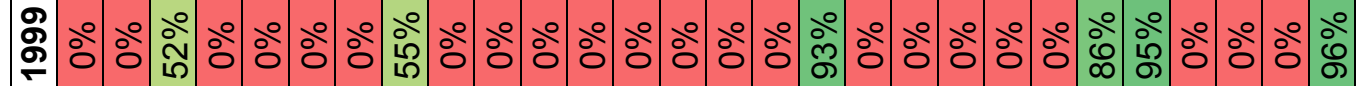

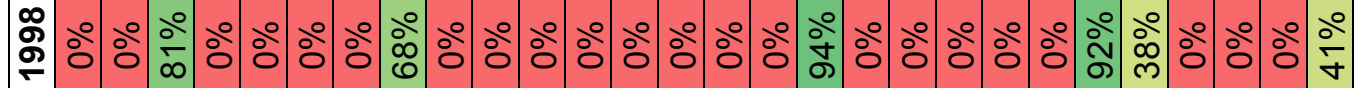
ஓి

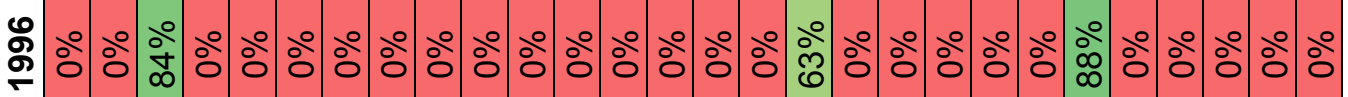

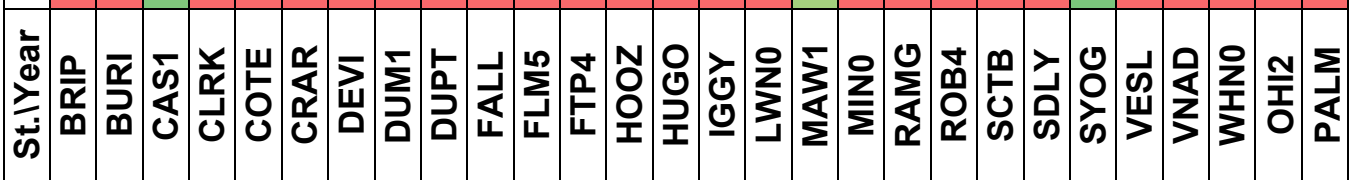




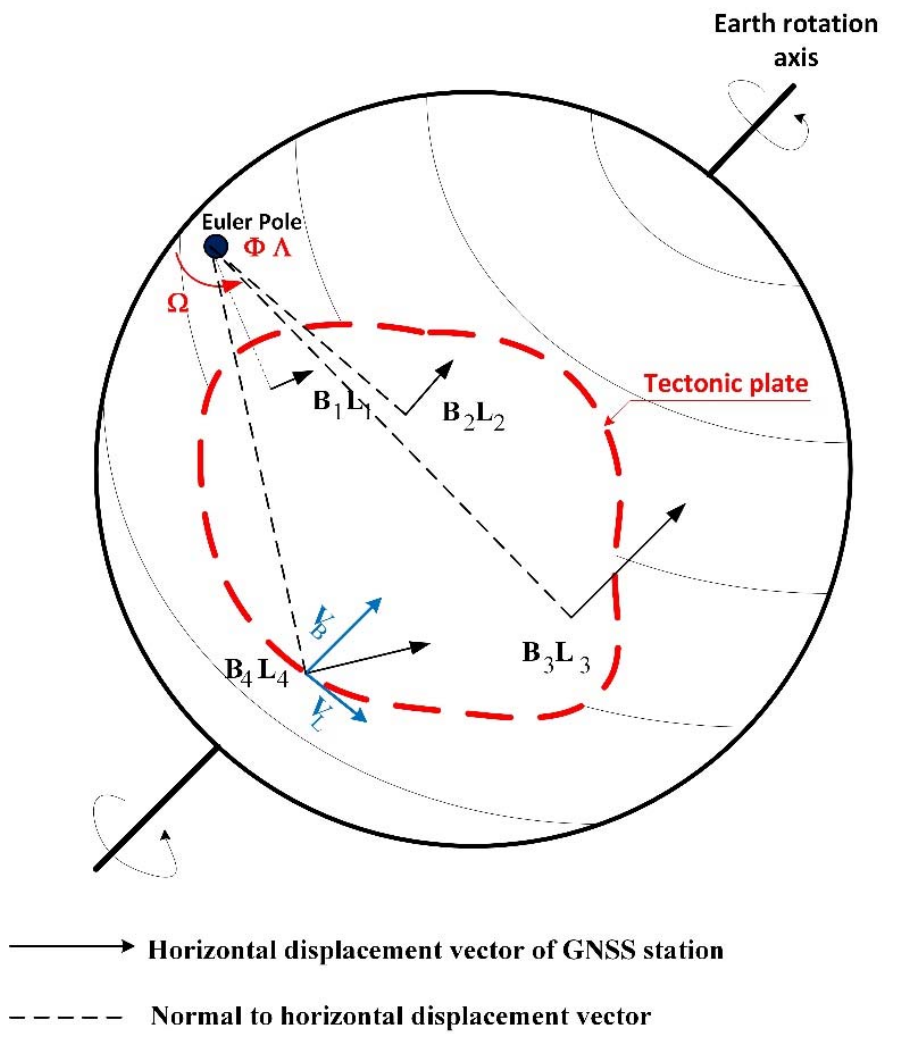

Fig. 3. Euler pole

For each point from the array of permanent stations, we can define nonlinear equations 1 and 2 . These equations have three unknowns: Euler pole coordinates, and angular velocity vector components. Depending on the number GNSS stations, the number of equations is greater than the number of unknowns (when $n \geq 2$, where $n-$ number of GNSS stations). Determination of unknown parameters $(\Omega, \Phi, \Lambda)$ can be done using the least squares method (Tretyak, 2016).

For this, we must differentiate equations (1), (2), and deduce them to the linear form:

$$
\begin{aligned}
& \delta_{\Omega} \cdot\left(\sin \left(L-\Lambda_{0}\right) \cdot \cos \left(\Phi_{0}\right)\right)-\delta_{\Phi} \cdot\left(\Omega_{0} \cdot \sin \left(L-\Lambda_{0}\right) \cdot \sin \left(\Phi_{0}\right)\right)- \\
& \delta_{\Lambda} \cdot\left(\Omega_{0} \cdot \cos \left(L-\Lambda_{0}\right) \cdot \cos \left(\Phi_{0}\right)\right)+\Omega_{0} \cdot \cos \left(\Phi_{0}\right) \cdot \sin \left(L-\Lambda_{0}\right)-\left(V_{B_{0}}-V_{B}\right)=v_{B} \\
& \quad \delta_{\Omega} \cdot\left(\cos (B) \cdot \sin \left(\Phi_{0}\right)-\cos \left(L-\Lambda_{0}\right) \cdot \sin (B) \cdot \cos \left(\Phi_{0}\right)\right)+ \\
& \quad+\delta_{\Phi} \cdot\left(\Omega_{0} \cdot\left(\cos (B) \cdot \cos \left(\Phi_{0}\right)+\cos \left(L-\Lambda_{0}\right) \cdot \sin (B) \cdot \sin \left(\Phi_{0}\right)\right)\right)- \\
& \quad-\delta_{\Lambda} \cdot\left(\Omega_{0} \cdot \sin \left(L-\Lambda_{0}\right) \cdot \sin (B) \cdot \cos \left(\Phi_{0}\right)\right)+ \\
& \quad \Omega_{0} \cdot\left(\sin \left(\Phi_{0}\right) \cdot \cos (B)-\cos \left(\Phi_{0}\right) \cdot \sin (B) \cdot \cos \left(L-\Lambda_{0}\right)\right)-\left(V_{L_{0}}-V_{L}\right)=v_{L}
\end{aligned}
$$

where $\delta_{\Omega}, \delta_{\Phi}, \delta_{\Lambda}$ - corrections to apriori values of Euler pole parameters $\left(\Omega_{0}, \Phi_{0}, \Lambda_{0}\right)$; $V_{B_{0}}$ and $V_{L_{0}}$ - apriori values of absolute velocity vector displacement of permanent GNSS station in latitude and longitude directions, determined using apriori values of Euler pole.

To determine the components of the horizontal velocity vector $V_{B}$ and $V_{L}$, we used daily time series of selected permanent GNSS stations (fig.4). 


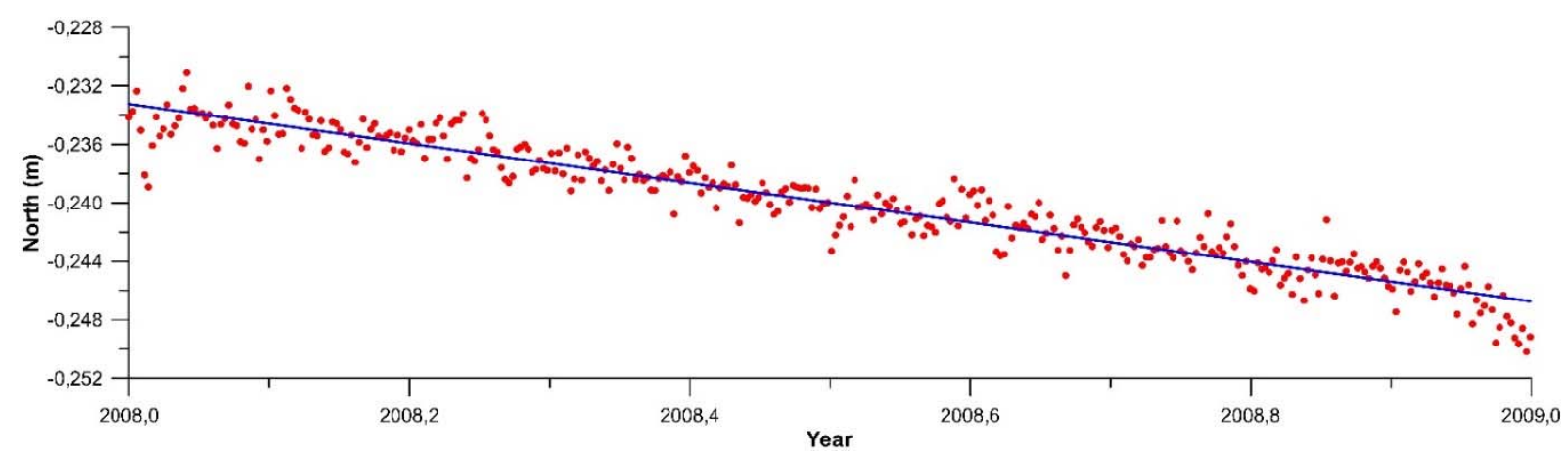

Fig. 4. Time series of permanent GNSS station BURI (North component)

For each solution, we can write the linear equations:

$$
\begin{aligned}
& x_{i}=V_{B} \cdot t_{i}+c_{B} \\
& y_{i}=V_{L} \cdot t_{i}+c_{L}
\end{aligned}
$$

were $t_{i}$ - observation epoch, $c_{B}, c_{L}$ are constants.

Using the least square method we separately solved the equations (5) and (6), determined components of velocity vectors $V_{B}, V_{L}$ and performed precision assessment of specified parameters $m_{V_{B}}$ and $m_{V_{L}}$.

Weights of each equation $(5-6)$ relates to continuity and uniformity of data distribution, during observation time. Fig. 4 shows continuous daily time series. A weight of continuity and uniformity for this time series equals to 1. Fig. 5 shows time series with gaps, and fig. 6 - time series with gaps and irregularities in the considered time span of data. Weights of these time series will be different from 1. For a weight computation it is necessary to determine observation interval length:

$$
\Delta t=t_{2}-t_{1}
$$

where $t_{1}, t_{2}$ - the starting and final epoch of observation, respectively.

Average length of time span of data is determined, consequently of number of solutions:

$$
S_{r}=\frac{t_{1}+t_{2}}{2}
$$

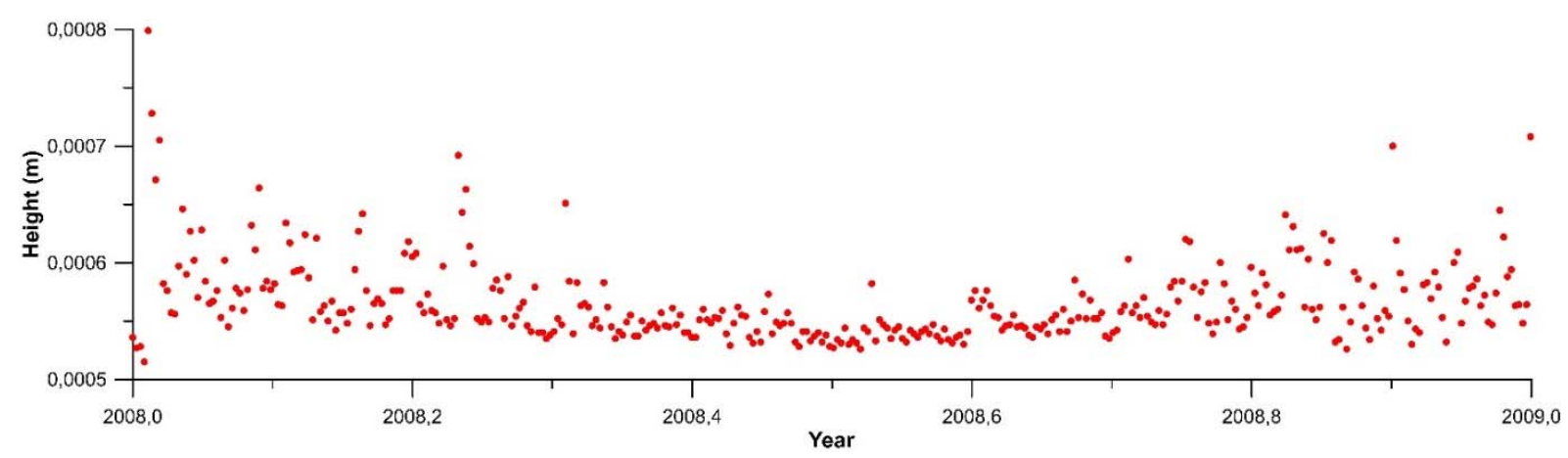

Fig. 5. Gaps in time series of permanent GNSS station BRIP (Height component) 


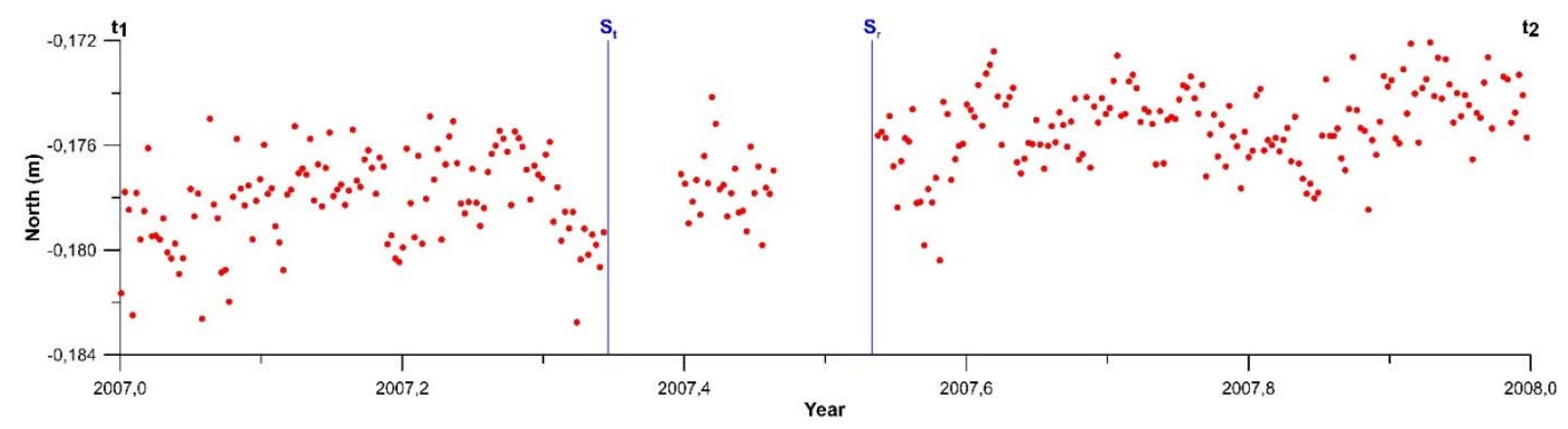

Fig. 6. Gaps and irregular variations in time series of permanent GNSS station SYOG (North component)

Average epoch of all existing solutions is computed as:

$$
s_{t}=\frac{\sum_{i=1}^{n} t_{i}}{n},
$$

where $t_{i}$ - epoch of $i$-th solution; $n$ - number of solutions which could be different from the average length of time span data $s_{r}$ (fig. 8).

A weight due to data irregularity is computed:

$$
P_{1}=1-\frac{2\left|s_{r}-s_{t}\right|}{\Delta t}
$$

The greater is a deviation, is a difference: $s_{r}-s_{t}$ the less is a weight, but if $s_{r}=s_{t}$, then the weight will be equal to 1 . Weight determination of data continuity can be done using the following expression:

$$
P_{2}=1-\frac{4\left|\frac{\Delta t}{4}-\delta t\right|}{\Delta t}
$$

where $\delta t=\frac{\sum\left|t_{i}-s_{t}\right|}{n}$-the sum of average residuals of epochs of all available solutions from $s_{t}$.

Final weight of vector components $V_{B}$ and $V_{L}$ is computed using the following expression:

$$
P=\frac{P_{1} P_{2}}{m^{2}}
$$

where $P_{1}$ - weight for data irregularity; $P_{2}$ - weight for data of continuity; $\mathrm{m}^{2}-$ it the r.m.s. of $m_{V_{B}}$ and $m_{V_{L}}$ residuals, respectively.

For each determined component of velocity vector $V_{B}$ and $V_{L}$, with appropriate weight $P$, using apriory values of Euler pole $\left(\Omega_{0}, \Phi_{0}, \Lambda_{0}\right)$ we composed correction equations $(3-4)$. Solving these equations, using the least square method we have got corrections $\left(\delta_{\Omega}, \delta_{\Phi}, \delta_{\Lambda}\right)$, and compute final values of Euler pole coordinates and angular velocity of tectonic plate $(\Omega, \Phi, \Lambda)$.

$$
\begin{aligned}
& \Omega=\Omega_{0}+\delta_{\Omega} \\
& \Phi=\Phi_{0}+\delta_{\Phi} \\
& \Lambda=\Lambda_{0}+\delta_{\Lambda}
\end{aligned}
$$


Using final parameters we computed model velocities of GNSS station, and determine the mean errors of Euler pole parameters $(\Omega, \Phi, \Lambda)$.

$$
\begin{aligned}
& m_{\Omega}=\mu \cdot \sqrt{Q_{\Omega \Omega}} \\
& m_{\Phi}=\mu \cdot \sqrt{Q_{\Phi \Phi}} \\
& m_{\Lambda}=\mu \cdot \sqrt{Q_{\Lambda \Lambda}}
\end{aligned}
$$

where : $Q_{\Omega \Omega}, Q_{\Phi \Phi}, Q_{\Lambda \Lambda}$ - diagonal elements of correlation matrix $\mu=v^{T} \cdot \frac{v}{2 n-1}$ - error unit of weight of measured velocity vectors, $v$-differences between the modeled and measured values of the velocity vectors.

Using the presented algorithm, we have determined the horizontal velocities of the Antarctic GNSS stations, their precision and weight for all time span of observations

\begin{tabular}{|c|c|c|c|c|c|c|c|c|c|}
\hline № & $\begin{array}{l}\text { Station } \\
\text { name }\end{array}$ & $\mathrm{B}\left[{ }^{\circ}\right]$ & $L\left[{ }^{\circ}\right]$ & $\begin{array}{c}V_{B} \\
\text { [MM] }\end{array}$ & $\begin{array}{c}V_{L} \\
{[\mathrm{MM}]}\end{array}$ & $\begin{array}{l}m_{V_{B}} \\
\text { [MM] }\end{array}$ & $\begin{array}{l}m_{V_{L}} \\
\text { [MM] }\end{array}$ & $P_{B}$ & $P_{L}$ \\
\hline 1 & BRIP & -75.796 & 158.469 & -12 & 8 & 2.1 & 2.1 & 0.371 & 0.371 \\
\hline 2 & BURI & -79.147 & 155.894 & -12 & 6 & 1.9 & 2.0 & 0.372 & 0.373 \\
\hline 3 & CAS1 & -66.283 & 110.52 & -10 & 2 & 0.7 & 0.7 & 0.969 & 0.969 \\
\hline 4 & CLRK & -77.34 & 218.126 & -3 & 17 & 3.7 & 3.4 & 0.262 & 0.263 \\
\hline 5 & COTE & -77.806 & 161.998 & -12 & 8 & 2.1 & 2.0 & 0.364 & 0.365 \\
\hline 6 & CRAR & -77.848 & 166.668 & -11 & 9 & 0.8 & 1.0 & 0.656 & 0.667 \\
\hline 7 & DEVI & -81.477 & 161.977 & -12 & 7 & 2.5 & 2.7 & 0.338 & 0.318 \\
\hline 8 & DUM1 & -66.665 & 140.002 & -12 & 8 & 1.0 & 1.0 & 0.833 & 0.914 \\
\hline 9 & DUPT & -64.805 & 297.183 & 10 & 12 & 3.1 & 3.2 & 0.303 & 0.303 \\
\hline 10 & FALL & -85.306 & 216.368 & -6 & 12 & 4.1 & 4.1 & 0.268 & 0.276 \\
\hline 11 & FLM5 & -77.533 & 160.271 & -12 & 8 & 1.5 & 1.6 & 0.407 & 0.556 \\
\hline 12 & FTP4 & -78.928 & 162.565 & -12 & 8 & 1.3 & 1.4 & 68 & 0.467 \\
\hline 13 & $\mathrm{HOOZ}$ & -77.532 & 166.933 & -11 & 11 & 1.3 & 1.7 & 0.691 & 0.623 \\
\hline 14 & HUGO & -64.963 & 294.332 & 10 & 15 & 4.4 & 4.3 & 0.251 & 0.295 \\
\hline 15 & IGGY & -83.307 & 156.25 & -13 & 4 & 3.1 & 4.2 & 0.320 & 0.290 \\
\hline 16 & LWNO & -81.346 & 152.732 & -12 & 4 & 2.4 & 2.4 & 0.325 & 0.368 \\
\hline 17 & MAW1 & -67.605 & 62.871 & -2 & -4 & 0.6 & 0.6 & 0.984 & 0.983 \\
\hline 18 & MINO & -78.65 & 167.164 & -11 & 9 & 3.9 & 3.9 & 0.339 & 0.314 \\
\hline 19 & RAMG & -84.338 & 178.047 & -11 & 9 & 2.1 & 2.0 & 0.362 & 0.363 \\
\hline 20 & ROB4 & -77.034 & 163.19 & -12 & 9 & 1.2 & 1.4 & 0.474 & 0.484 \\
\hline 21 & SCTB & -77.849 & 166.758 & -12 & 9 & 1.3 & 1.2 & 0.543 & 0.525 \\
\hline 22 & SDLY & -77.135 & 234.025 & 1 & 19 & 5.5 & 3.9 & 0.252 & 0.249 \\
\hline 23 & SYOG & -69.007 & 39.584 & 3 & -4 & 0.6 & 0.6 & 0.981 & 0.980 \\
\hline 24 & VESL & -71.674 & 357.158 & 10 & 0 & 0.7 & 0.7 & 0.821 & 0.923 \\
\hline 25 & VNAD & -65.246 & 295.746 & 10 & 14 & 3.2 & 3.3 & 0.303 & 0.303 \\
\hline 26 & WHNO & -79.846 & 154.22 & -13 & 5 & 2.2 & 2.3 & 0.356 & 0.354 \\
\hline 27 & $\mathrm{OHI} 2$ & -63.321 & 302.099 & 10 & 15 & 1.6 & 1.9 & 0.671 & 0.667 \\
\hline 28 & PALM & -64.775 & 295.949 & 11 & 13 & 0.9 & 0.7 & 0.852 & 0.869 \\
\hline
\end{tabular}
(Table 3).

Table 3. Determined GNSS stations velocity vectors 
The table 3, shows that average precision of vector components equal to about $10 \%$ of their length. Fig. 7 shows the map of velocity vectors of the Antarctic GNSS stations for the period of $1996-2014$. As we can see, the vectors have a rotational character that move in the clockwise direction.

For all time span of data, we computed average values of angle velocity and Euler pole coordinates for the Antarctic tectonic plate. Assessment of precision and root mean-square errors of computed horizontal velocities $m_{V_{p}}$, are given in Table 4.

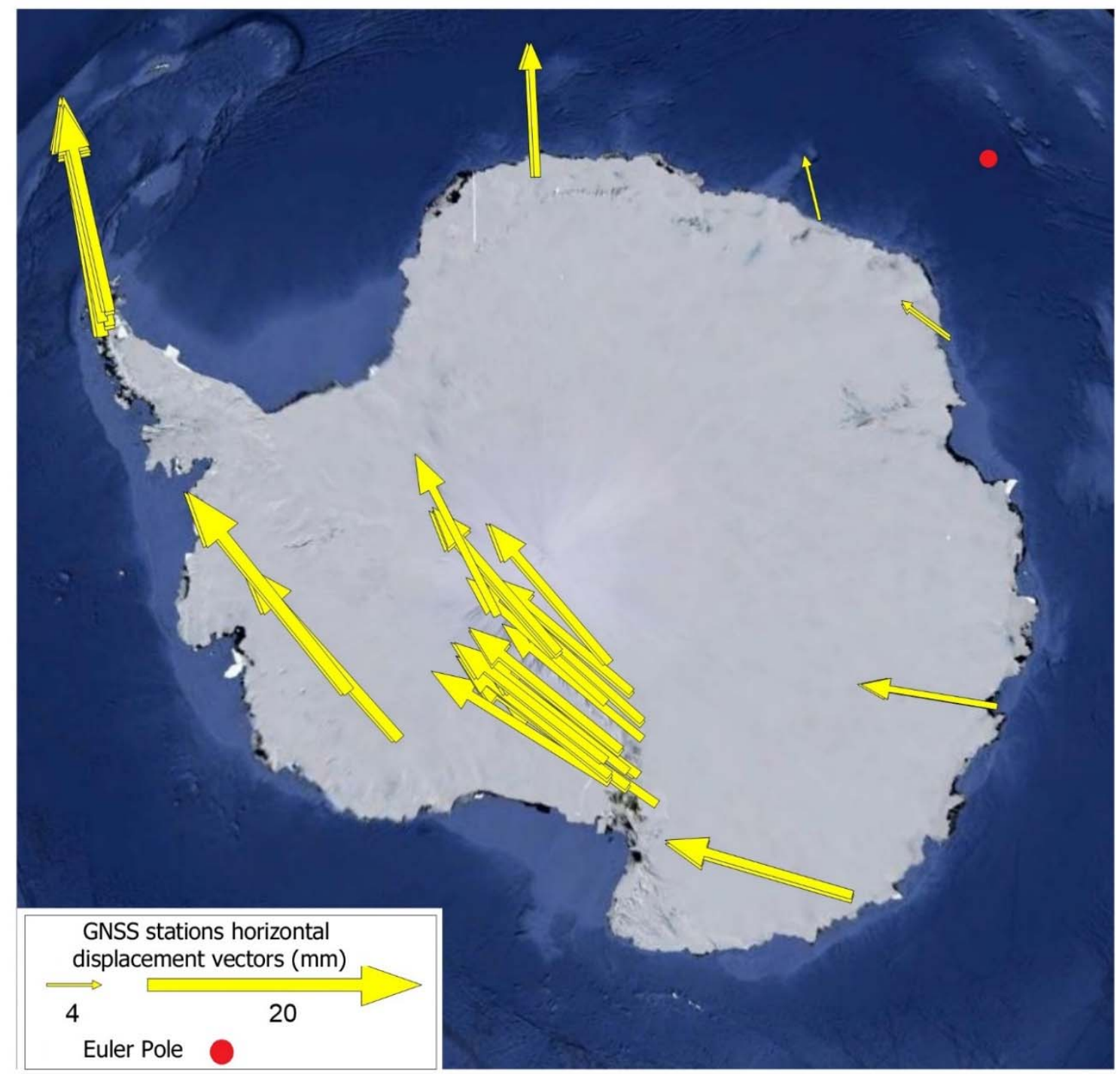

Fig. 7. Velocity vectors of the Antarctic GNSS stations for the period of $1996-2014$

Table 4. Average values of the angular velocity and Euler pole coordinates, of the Antarctic tectonic plate

\begin{tabular}{|c|c|}
\hline$\omega[$ ["/year] & 0.00074 \\
\hline$\Phi\left[{ }^{\circ}\right.$ Euler pole] & 58.2157 \\
\hline$\Lambda$ [ ${ }^{\circ}$ Euler pole] & 52.9937 \\
\hline$m_{\omega}[$ “'/year] & 0.000008 \\
\hline$m_{\Phi}\left[{ }^{\circ}\right]$ & 0.308 \\
\hline$m_{\Lambda}\left[{ }^{\circ}\right]$ & 0.416 \\
\hline$m_{V_{p}}[\mathrm{~mm} /$ year] & 0.9 \\
\hline
\end{tabular}


The precision of the angular velocity determination is two orders less than the velocity values, and precision of stations velocities determination equals to about 1 $\mathrm{mm} /$ year.

Figure 8 shows the positions of Euler poles, determined as average for the period (1996 - 2014) in this paper, and other papers (Drewes, 1998, 2001, 2009; Argus, 1991, 2011; SOPAC, 2016; Altamimi, 2012; Dietrich, 2001, 2004; Sella, 2002; Jiang WeiPing, 2009).

As we can see from the figure 8 the computed Euler pole is located nearby to the pole computed by SCAR for time period $1997-2004$.

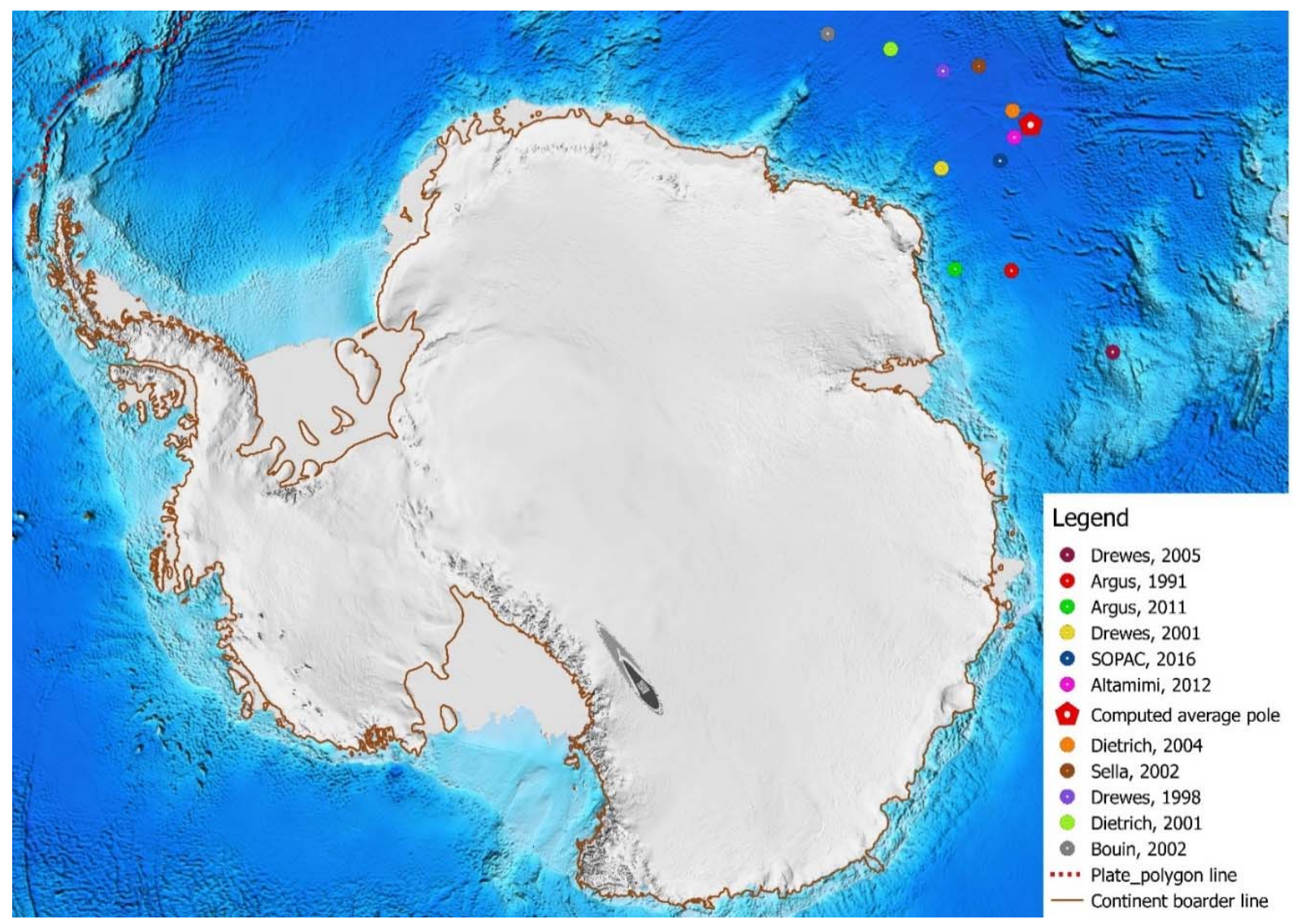

Fig. 8. Euler poles of Antarctic tectonic plate

Using the results of computation of GNSS station yearly velocities we determined yearly parameters of Euler pole of the Antarctic tectonic plate and its angular velocities (table 5). Yearly migration of Euler pole is shown in fig.9. Fig. 10 a, b, and c shows yearly changes of latitude and longitude of Euler pole and angular velocity of the Antarctic tectonic plate.

From the fig. $11(a, b, c)$ we can see the connection between the changes of Euler pole latitude and its angular velocity. The decrease of the angular velocity leads to the decrease of the Euler pole latitude, and conversely, respectively. 


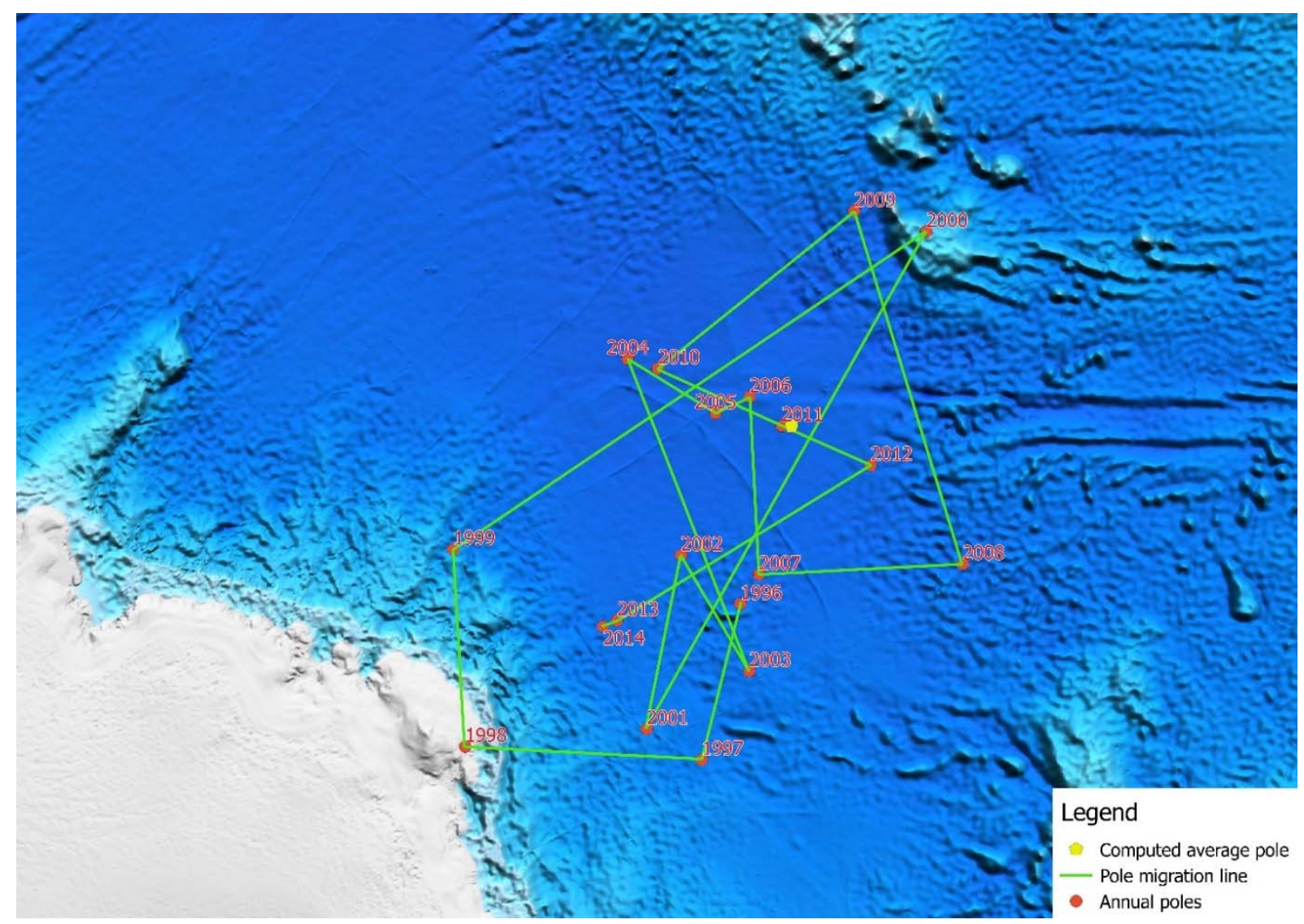

Fig. 9 Movement of the Antarctic plate Euler pole, computed from GNSS observations in the time period of $1996-2014$

Table 5. Determined yearly parameters of Euler pole (angular velocity and pole coordinates), and its precision assessment

\begin{tabular}{|c|c|c|c|c|c|}
\hline Years & 1996 & 1997 & 1998 & 1999 & 2000 \\
\hline$\omega$ ["/year] & 0.00083 & 0.00118 & 0.00103 & 0.00094 & 0.00071 \\
\hline$\Phi\left[{ }^{\circ}\right.$ Euler pole $]$ & 60.7776 & 62.8070 & 66.3532 & 64.3146 & 54.2651 \\
\hline$\Lambda\left[^{\circ}\right.$ Euler pole $]$ & 57.0776 & 61.4130 & 55.7144 & 48.5908 & 50.7945 \\
\hline$m_{\omega}[" / y e a r]$ & 0.00010 & 0.00011 & 0.00020 & 0.00008 & 0.00005 \\
\hline$m_{\Phi}\left[{ }^{\circ}\right]$ & 1.90520 & 0.91235 & 2.45059 & 1.69567 & 2.52444 \\
\hline$m_{\Lambda}\left[{ }^{\circ}\right]$ & 3.18467 & 1.55628 & 6.95636 & 3.79690 & 3.11984 \\
\hline$m_{V_{p}}[\mathrm{~mm}]$ & 0.8 & 0.7 & 7.0 & 3.0 & 1.5 \\
\hline Years & 2001 & 2002 & 2003 & 2004 & 2005 \\
\hline$\omega$ [“/year] & 0.00084 & 0.00079 & 0.00083 & 0.00076 & 0.00075 \\
\hline$\Phi\left[{ }^{\circ}\right.$ Euler pole] & 63.3941 & 61.1644 & 61.2747 & 59.6926 & 59.1372 \\
\hline$\Lambda\left[{ }^{\circ}\right.$ Euler pole] & 59.2602 & 54.3568 & 59.3592 & 47.6225 & 51.0585 \\
\hline$m_{\omega}[$ ["/year] & 0.00003 & 0.00005 & 0.00003 & 0.00003 & 0.00002 \\
\hline$m_{\Phi}\left[{ }^{\circ}\right]$ & 1.88183 & 1.74935 & 1.29964 & 1.32376 & 0.67070 \\
\hline$m_{\Lambda}\left[{ }^{\circ}\right]$ & 4.84780 & 2.81064 & 2.05997 & 1.87300 & 0.97277 \\
\hline$m_{V_{p}}[\mathrm{~mm}]$ & 1.8 & 2.5 & 1.6 & 1.3 & 3.6 \\
\hline
\end{tabular}


Table 5. (cont.) Determined yearly parameters of Euler pole (angular velocity and pole coordinates), and its precision assessment

\begin{tabular}{|c|c|c|c|c|c|}
\hline Years & 2006 & 2007 & 2008 & 2009 & 2010 \\
\hline$\omega$ ["/year] & 0.00077 & 0.00076 & 0.00078 & 0.00074 & 0.00075 \\
\hline$\Phi\left[{ }^{\circ}\right.$ Euler pole] & 58.4879 & 60.2095 & 57.0464 & 54.9920 & 59.4045 \\
\hline$\Lambda\left[^{\circ}\right.$ Euler pole] & 51.3520 & 56.5518 & 59.8963 & 48.9331 & 48.5756 \\
\hline$m_{\omega}$ [“/year] & 0.00003 & 0.00002 & 0.00002 & 0.00002 & 0.00003 \\
\hline$m_{\Phi}\left[{ }^{\circ}\right]$ & 1.37698 & 0.74816 & 1.06245 & 1.11181 & 1.38743 \\
\hline$m_{\Lambda}\left[{ }^{\circ}\right]$ & 1.62137 & 1.00725 & 1.01728 & 0.86209 & 1.42594 \\
\hline$m_{V_{p}}[\mathrm{~mm}]$ & 1.5 & 5.8 & 11.5 & 6.6 & 3.1 \\
\hline Years & 2011 & 2012 & 2013 & 2014 & \\
\hline$\omega$ ["/year] & 0.00081 & 0.00070 & 0.00089 & 0.00085 & \\
\hline$\Phi\left[{ }^{\circ}\right.$ Euler pole] & 58.3523 & 57.4884 & 62.7808 & 63.0495 & \\
\hline$\Lambda \quad{ }^{\circ}$ Euler pole $]$ & 52.7899 & 55.5839 & 54.9790 & 54.8560 & \\
\hline$m_{\omega}$ ["/year] & 0.00003 & 0.00002 & 0.00003 & 0.00004 & \\
\hline$m_{\Phi}\left[{ }^{\circ}\right]$ & 1.42683 & 1.32607 & 1.13422 & 1.44046 & \\
\hline$m_{\Lambda}\left[{ }^{\circ}\right]$ & 1.38077 & 1.26414 & 1.27073 & 1.71990 & \\
\hline$m_{V_{p}}[\mathrm{~mm}]$ & 2.6 & 1.3 & 3.0 & 4.9 & \\
\hline
\end{tabular}

\section{Conclusions}

1) The modified algorithm for determination coordinates of Euler pole and the angular velocity of tectonic plates motions was developed, with consideration of the continuity and irregularity of GNSS time series.

2) Using observation results of 28 permanent GNSS stations, located in Antarctica, for the period of time 1996 - 2014, the average coordinates of Euler pole and angular velocity of the Antarctic tectonic plate were determined, together with their annual changes.

3) The comparison of the annual changes of determined Euler pole parameters showed the presence of the relationship between the changes of Euler pole latitude and angular velocity of the Antarctic tectonic plate. Obviously by the change of Euler's pole coordinates is related with conservation of angular momentum of the Antarctic tectonic plate. 


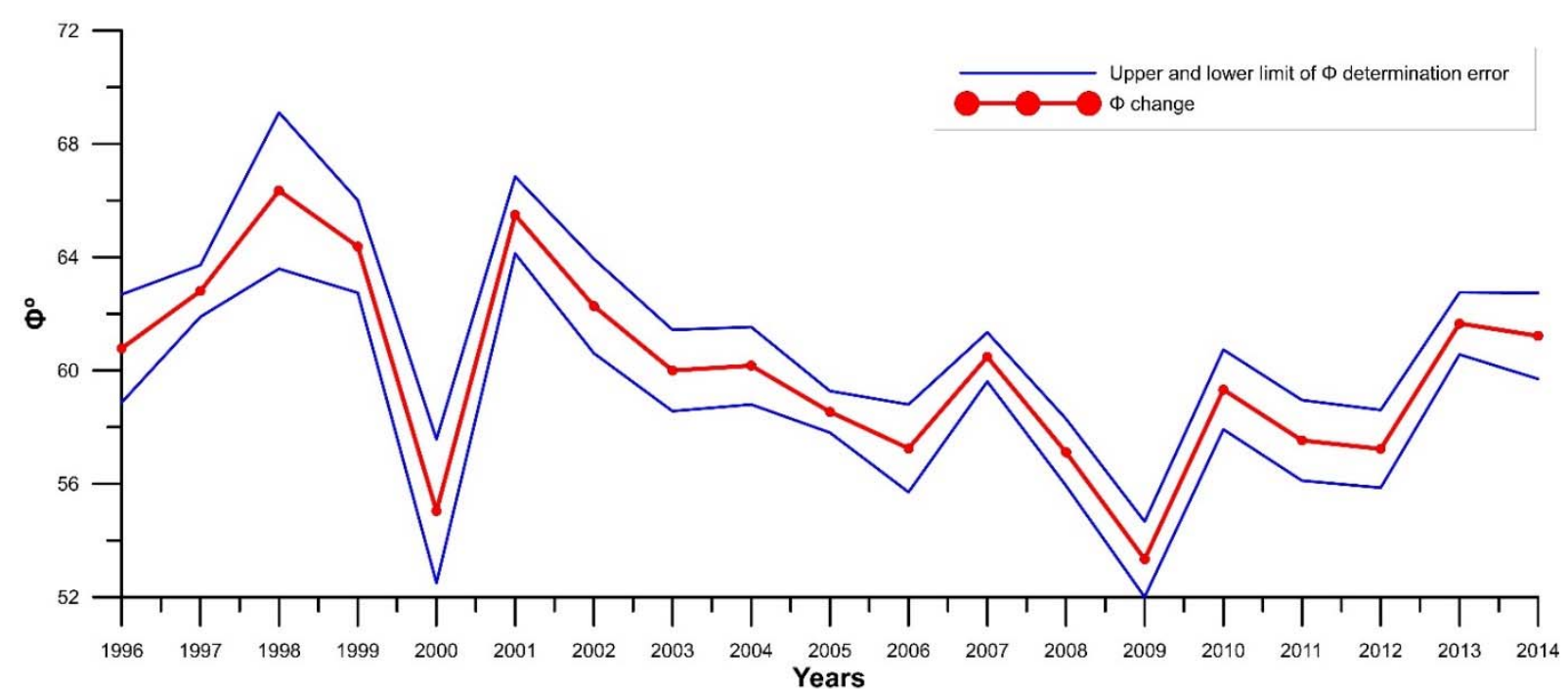

a)

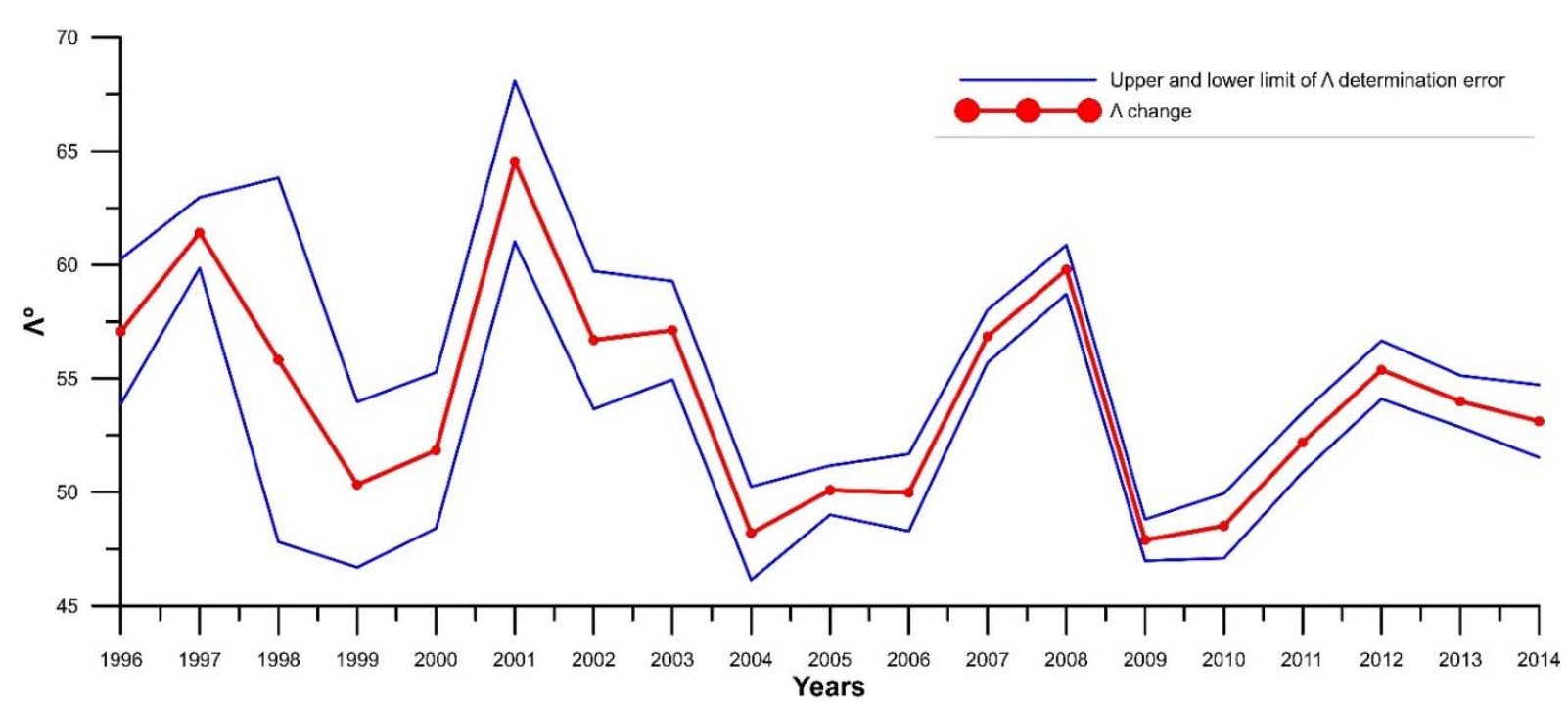

b)

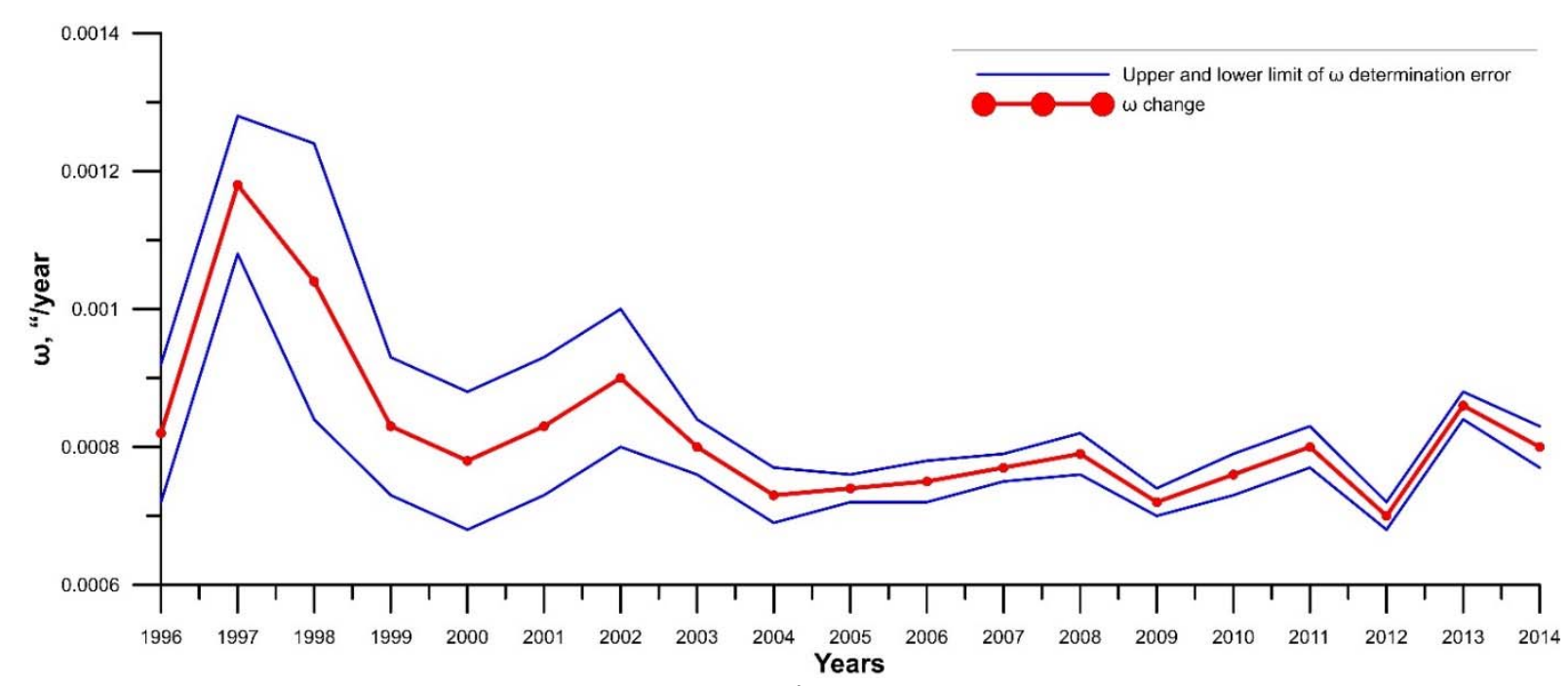

c)

Fig. 10. Changes of the average annual parameters of Euler pole and angular velocity of the Antarctic tectonic plate and angular velocity of the Earth in the time period of $1996-2014$. a) latitude $\Phi ;$ b) longitude $\Lambda$; c) angular velocity of the Antarctic plate $\omega$; 


\section{References}

Altamimi, Z., L. Métivier, \& X. Collilieux (2012), ITRF2008 plate motion model, J. Geophys. Res., 117, B07402,

Argus, D. F., Gordon, R. G., \& DeMets, C., (2011). Geologically current motion of 56 plates relative to the no-net-rotation reference frame. Geochemistry, Geophysics, Geosystems, vol.12, no.11, DOI: 10.1029/2011GC003751

Argus, D.F. \& R.G. Gordon, (1991). No-net-rotation model of current plate velocities incorporating plate motion model NUVEL-1, Geophys. Res. Lett., 18, 2039-2042.

Bowin, C. (2010). Plate tectonics conserves angular momentum, eEarth, 5, 1-20, DOI:10.5194/ee-5-1-2010.

Berrocoso M., Fernández-Ros A., Prates G., García A. \& Kraus S. (2016). Geodetic implications on block formation and geodynamic domains in the South Shetland Islands, Antarctic Peninsula, Tectonophysics 666 (2016) 211-219.

Capra A., Gandolfi S., Mancini F.,Sarti P. \& Vittuari L. (2002),"VLNDEF project for crustal deformation control of northern Victoria land" AGS '01 (Antarctic Geodesy Symposium), St.Petersburg, 2002, N.21, pp.8-10

Capra, A., Dubbini, M., Galeandro, A., Gusella, L., Zanutta, A., Casula, G., Negusini, M., Vittuari, L., Sarti, P., Mancini, F., Gandolfi, S., Montaguti, M. \& Bitelli, G. (2008), VLNDEF project for geodetic infrastructure definition for Northern Victoria Land. Antarctica Geodetic and geophysical observation in Antarctica An overview in the IPY perspective, Springer, 2008, pp. 1-11

Dalziel, I.W.D., Smalley, R., Kendrick, E., Bevis, M., \& Taylor, F.W. (2006) The West Antarctic GPS Network. GPS in the International Polar Year, The POLENET Project Workshop. Dresden, Germany. 04-06 October 2006.

Dietrich R. \& Rulke A. (2008) A precise reference frame for antarcica from SCAR GPS campaing data and some geophysical implications Geodetic and geophysical observation in Antarctica An overview in the IPY perspective, Springer, pp. 1-11

Dietrich R., Dach R. \& Engelhardt G. (2001). ITRF coordinates and plate velocities from GPS campaigns in Antarctica - an analysis based on different individual solutions. Journal of Geodesy Vol.74, No.11, 756-766.

Dietrich, R., Rülke, A., Ihde, J., Lindner, K., Miller, H., Niemeier, W., Schenke, H. W. \& Seeber, G. (2004). Plate kinematics and deformation status of the Antarctic Peninsula based on GPS. Global and Planetary Change, 42 (1), pp. 313-321. DOI: 10.1016/j.gloplacha.2003.12.003

Donnellan, A. \& Luyendyk B. (1999) GPS measurement of isostatic rebound and tectonic deformation in Marie Byrd Land, West Antarctica GPS99 and Asian Pacific Space Geodynamics Program, Abstracts, 1999, Japan, 07-15

Donnellana A. \& Luyendyk Bruce P. (2004), GPS evidence for a coherent Antarctic plate and for postglacial rebound in Marie Byrd Land Global and Planetary Change, Vol. 42, pp. $305-311$

Drewes, H. (2009). The Actual Plate Kinematic and Crustal Deformation Model APKIM2005 as basis for a non-rotating ITRF, Geodetic Reference Frames, H. Drewes (Ed.), IAG Symposia, 134, 95-99, Springer, DOI:10.1007/978-3-642-008603_15, 2009.

Drewes, H., (1998). Combination of VLBI, SLR and GPS determined station velocities for actual plate kinematic and crustal deformation models. In: M. Feissel (Ed.): Geodynamics, IAG Symposia, Springer 1998.

Drewes, H., \& D. Angermann, (2001). The Actual Plate Kinematic and Crustal Deformation Model 2000 (APKIM2000) as a Geodetic Reference System, AIG 2001 Scientific Assembly, Budapest 
International Earth Rotation Service [Electronic resource]: IERS. - link: https://www.iers.org

Jiang Wei-Ping, (2009). New Model of Antarctic Plate Motion and Its Analysis. Chinese Journal of Geophysics Vol.52, No.1. 23-32.

Johnstone G. (2002) SCAR Geodetic Control Database, Antarctic Geodesy Symposium 2002 Wellington, New Zealand, 25-27

Konovalov G.V. \& Mekkel A.M. (2009) Shkaly vremeni: istoriya, reglamentatsiya v rekomendatsiyakh MSE i voploshcheniyev modelyakh. Naukovi zapiski (Proceedings), 3 (11), $4-16$.

Marchenko O. M., Tretyak K. R., Kulchyckyj A. Ya., Holubinka Yu. I., Marchenko D. O. \& Tretyak N. P. (2012) Doslidzhennya hravitacijnoho polya, topohrafiyi okeanu ta ruxiv zemnoyi kory v rehioni Antarktyky. Lviv, Vydavnyctvo Lvivkoyi politexniky (Lviv Polytechnic Publisher), 306.

Nevada Geodetic Laboratory [Electronic resource]: NGL. - link: http://geodesy.unr.edu/index.php

Nield Grace A., Barletta Valentina R., Bordoni Andrea, King Matt A., Whitehouse Pippa L., Clarke Peter J., Domack Eugene, Scambos Ted A. \& Berthier Etienne (2014). Rapid bedrock uplift in the Antarctic Peninsula explained by viscoelastic response to recent ice unloading, Earth and Planetary Science Letters 397 (2014) 32-41

Pandul Y.S. (2010) Heodezycheskaya astronomyya prymenytelno k reshenyyu ynzhenerno-heodezycheskyx zadach. SPb. Polytexnyka (Polytechnic), 328. ISBN 978-5-7325-0924-3

Scientific Committee on Antarctic Research [Electronic resource]: SCAR http://www.scar.org/

Script Orbit and Permanent Array Center [Electronic resource]: SOPAC. - link: http://sopac.ucsd.edu/

Sella, G.F., T.H. Dixon, \& A. Mao (2002). REVEL: A model for recent plate velocities from space geodesy. J. Geophys. Res., 107, B4, DOI:10.1029/2000JB000033, 2002.

Sydorenkov N.S. (2004), Pryroda nestabylnostej vrashhenyya Zemly, Pryroda [Nature], 8, 8 - 18.

Tretyak K.R. \& Holubinka Yu.I. (2006). Ocinka ta dyferenciaciya ruxiv Zemnoyi kory Antarktydy, UAZh, № 4-5, 72-83

Tretyak K.R. \& Vovk A.I. (2016). Differentation of the rotational movements of the european continents earth crust. Acta Geodynamica et Geomaterialia, Vol. 13, No. 1 (181), 5 - 18. DOI: 10.13168/AGG.2015.0046

Zharov V.Y. (2002). Sfericheskaya astronomiya, Moskva, 480.

Zotov L.V. (2005). Vrashcheniye Zemli:analiz variatsiy i ikh prognozirovaniye. Gosudarstvennyy astronomicheskiy institut im. P.K. Shternberga. MGU, g. Moskva.

\section{Author:}

Kornyliy Tretyak ${ }^{1)}$, Prof. Dr.habil.,kornel@lp.edu.ua

Holubinka Yuriy1), Ph.D., iurii.golubinka@gmail.com

Al-Alusi Forat ${ }^{1)}$, Ph.D. student,

1) National University Lviv Polytechnic. Institute of Geodesy.

79013 Lviv, 12 Bandera street, Ukraine. 